\title{
Characterization of Activated Carbon Prepared from Almond Shells for Scavenging Phenolic Pollutants
}

\author{
P. K. CHAYANDE ${ }^{* a}$, S .P. SINGH ${ }^{\mathrm{a}}$ and M. K. N. YENKIE ${ }^{\mathrm{b}}$ \\ ${ }^{a}$ Central Institute of Mining and Fuel Research, Nagpur. Maharashtra, India \\ ${ }^{\mathrm{b}}$ Laxminarayan Institute of Technology, Nagpur, Maharashtra, India \\ pragyapatil@rediffmail.com
}

Received 19 August 2012 / Accepted 19 September 2012

\begin{abstract}
The present work comprises study of almond shell activated carbon (ASAC) impregnated by $\mathrm{H}_{3} \mathrm{PO}_{4}$ used as adsorbent. The objective of this work was to determine the ability of activated carbon in phenol removal. The activated carbon in the study was of size +1 to $-4.75 \mathrm{~mm}$. ASAC is found to be inexpensive and effective adsorbent for removal of phenol from aqueous solution. Prepared activated carbon was characterized by determining Iodine number and methylene blue number to examine the extent and nature of porosity. The higher methylene blue number demonstrates that fairly mesoporous carbon has been developed by the process which can facilitate its applicability as potential dye removal adsorbent. $\mathrm{N}_{2} \mathrm{BET}$ surface area has been found to be quite comparable to commercially available carbon. The FTIR results strongly support significant spectral and chemical changes occurring with the activation of the almond shells for phosphoric acid treatment. The physical morphology clearly shows that the data obtained is consistent to the structural surface as determined by analyzing the SEM micrographs.
\end{abstract}

Keywords: SEM, FTIR, Almond shells, Adsorption, Methylene blue number

\section{Introduction}

Pollutants in water such as phenol, phenolic compounds, aldehydes, aromatic and aliphatic compound is of great public concern now a days ${ }^{1-3}$. These compounds are by-products of different types of processes in the industries. Before discharging to water bodies, it must be treated. Activated carbon, a porous adsorbent, is widely used in industry in the purification of liquids and gases. For example, a liquid which is to be purified is passed through a bed of granular activated carbon. As the liquid passes through the activated carbon bed, molecules of impurities in the liquid are adsorbed onto the surface of the activated carbon. Consequently, the larger the surface area of the activated carbon the more efficient the filter will be in removing impurities ${ }^{4}$. There is dramatically increase in use of activated carbon (AC) for adsorption of organic pollutants during last few decades in treatment of drinking water and industrial effluents ${ }^{5,6}$. The porous structure of an Activated carbon is a function of the source material used in the preparation of carbon, the activation procedure and the extent 
of activation. The operational cost for preparation of AC is expensive because of its production by treating chemically carbonaceous materials such as coal, wood, nutshell so that it develops internal pores that yield its characteristic high surface ${ }^{7}$. The starting materials are selected to have a concentration of natural binding agent greater than $30 \%$ by weight. Due to depletion of natural conventional resources such as coal, researchers are diverted to develop activated carbon from other carbonaceous materials including waste.

There are a number of such uses for activated carbons from the removal of coloured compounds present as impurities in the products of a chemical reaction to the purification of gases prior to discharge to the atmosphere to produce carbon for dye removal. Chemical activation with phosphoric acid, zinc chloride, or carbonate salts was used for activation of almond shells ${ }^{8}$. Earlier researchers have found application of activated carbon in metal adsorption $^{9,10}$. The present research paper report studies on the activated carbon made from almond shell using phosphoric acid.

\section{Experimental}

Almond shells were collected from local market as sweet industry waste. The raw material was ground to small pieces using hand crusher. Material was oven dried at $180{ }^{\circ} \mathrm{C}$ for about $2 \mathrm{~h}$. This process was done to mildly oxidize shells so that volume of reactive sites will be available for activation. $10 \mathrm{~g}$ of refluxed nutshells were weighed exactly and impregnated with $\mathrm{H}_{3} \mathrm{PO}_{4}$ in $1: 2$ ratios for $48 \mathrm{~h}$ and carbonized at $850{ }^{\circ} \mathrm{C}$ in furnace reactor for two hours. The main objective of impregnation was to make the mixture of the chemical and the precursor homogeneous, previous works have shown that impregnation also brings about the transformation of the precursor ${ }^{11-13}$. The furnace reactor has the facility to heat the material from room temperature to $850{ }^{\circ} \mathrm{C}$ and the temperature was controlled to an accuracy of $\pm 5^{\circ} \mathrm{C}$ by means of a temperature controller. During carbonization the carbonaceous material along with the impregnation agent turns black forming a plastic mass, which turns into a dry powder on continued heating. The carbonized material was cooled to room temperature and washed thoroughly with $5 \mathrm{~N} \mathrm{HCl}$ until excess acid was totally removed and the $\mathrm{pH}$ of the washed water was neutral. After washing the material was dried at $105{ }^{\circ} \mathrm{C}$ overnight and meshed into $325 \mathrm{~mm}$ size with the help of sieve and was used for further experiments for characterization of prepared activated carbon.

\section{Preparation of stock solution for adsorption studies}

All the reagents used were of analytical grade. A fresh aqueous solution of phenol was prepared using boiled distilled water cooled to room temperature. The solutions of twelve different concentrations varying from $0.0001-0.0025(\mathrm{~mol} / \mathrm{g})$ were prepared by adding required amount of stock solution for each concentration in $250 \mathrm{~mL}$ of volumetric flask and diluting it to make up the volume with boiled and cooled distilled water .

\section{Results and Discussion}

Two commercially available standard activated carbons were used in this study for comparison, a bituminous coal based F-400 procured from calgon corporation, USA and coconut shell based Activated carbon from S.D.fine chemicals, Mumbai.

The data obtained for physicochemical properties of raw almond shell, activated almond shell, F-400 are shown in Table 1 illustrate that as compared to F-400, almond shell activated carbon has higher ash content $8.19 \%$, higher volatile matter $16 \%$ with decreasing fixed carbon content of $57.32 \%$. Also from raw almond shells to activated carbon fixed carbon considerably increased as consistent with the findings of other researchers ${ }^{14}$. 
The values describing Brunaur Emmett Teller surface area (BET), Iodine and methylene blue (MB) numbers of the ACs shown in Tables 2 and 3 respectively illustrates that the prepared activated carbon have better application in dye removal compared to commercially available AC. Figure $2 \& 3$ represents SEM micrographs and Figure 4 represents results for FTIR analysis for the studied AC.

Table 1. Physicochemical analysis of prepared activated carbon

\begin{tabular}{cccccccc}
\hline $\begin{array}{c}\text { Activated } \\
\text { Carbon }\end{array}$ & M\% & Ash\% & V.M\% & F.C\% & C\% & H\% & N\% \\
\hline F-400 & 5.4 & 5.5 & 2.7 & 86.4 & 95.32 & 0.27 & - \\
Raw AS & 9.91 & 2.10 & 68.81 & 19.18 & 44.63 & 6.320 & 0.770 \\
ASAC & 18.49 & 8.19 & 16.0 & 57.32 & 63.76 & 2.543 & 0.812 \\
\hline \multicolumn{7}{c}{ M-Moisture; A-Ash V.M-Volatile Mater; F.C-Fixed Carbon } &
\end{tabular}

Table 2. Phenol-B.E.T adsorption isotherm data

\begin{tabular}{ccc}
\hline Activated carbon & $\mathrm{Q}^{\circ}, \mathrm{mol} / \mathrm{g}$ & $\mathrm{z}$ \\
\hline F-400 & 18.51 & 4928.5 \\
ASAC & 11.74 & 2440.0 \\
\hline
\end{tabular}

Table 3. Results for iodine number and methylene blue number

\begin{tabular}{cccc}
\hline Activated carbon & $\begin{array}{c}\text { Iodine number, } \\
\mathrm{mg} / \mathrm{g}\end{array}$ & $\begin{array}{c}\text { Methylene blue } \\
\text { number }\end{array}$ & $\begin{array}{c}\text { B.E.T surface } \\
\text { area, } \mathrm{m}^{2} / \mathrm{g}\end{array}$ \\
\hline F-400 & 1050 & 262 & - \\
S.D.Fine chemicals & 1053 & 143 & - \\
ASAC & 1134 & 387 & 1358 \\
\hline
\end{tabular}

\section{Adsorption isotherm}

The sorption capacity was determined by contacting various concentration twelve different concentrations varying from $0.0001-0.0025(\mathrm{~mol} / \mathrm{g})$ in $100 \mathrm{~mL}$ phenol solution with $0.1 \mathrm{~g}$ almond shell activated carbon. The mixture was shaken continuously on an electronic automatic shaker for 3 days at the speed of $250 \mathrm{rpm}$. The sample was then filtered through Whatman filter paper No 1. The initial and final concentration of phenol was analyzed on UV-Vis spectrophotometer-Perkin Elmer Lambda 25" at $\lambda_{\max } 660 \mathrm{~nm}$. The amount of adsorption at equilibrium $\left(\mathrm{Q}_{\mathrm{e}} \mathrm{mg} / \mathrm{g}\right)$ and sorption efficiency $(\%)$ were calculated according to the expressions;

$$
\begin{gathered}
q_{e}(m g / g)=\frac{\left[\left(c_{o}-c_{e}\right) V\right]}{m} \\
\text { Sorption efficiency } \%=\frac{\left.\left(c_{o}-c\right)\right]}{c_{o}} x 100
\end{gathered}
$$

Where $C_{o}$ and $C_{e}$ are the initial and equilibrium concentration $(\mathrm{mg} / \mathrm{L}), \mathrm{V}$ the volume of solution $(\mathrm{L}), \mathrm{m}$ the weight of almond shells activated carbon $(\mathrm{g})$ and $\mathrm{C}$ is the solution concentration at the end of the sorption process $(\mathrm{mg} / \mathrm{L})^{15}$. Figure 1 shows the B.E.T isotherms obtained for phenol adsorption on ASAC and F-400 that illustrate the synthesis of microporous structures with a good surface area and micropore volume. The isotherm is a type I for solids with large numbers of micropores as well as mesopores. The adsorption of phenol was found to be $11.74(\mathrm{~mol} / \mathrm{g})$ in comparison to $18.51(\mathrm{~mol} / \mathrm{g})$ for F-400. 


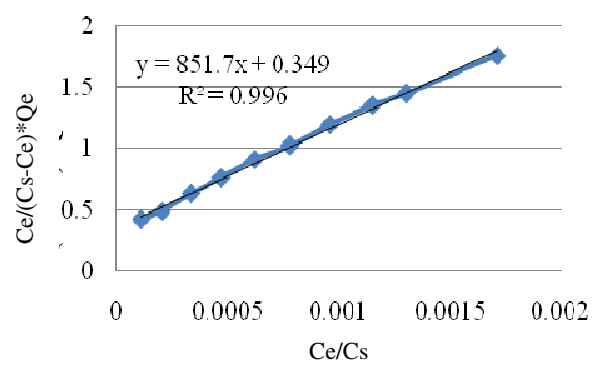

Figure 1. B.E.T adsorption isotherm of phenol on ASAC

\section{Characterization of adsorbent}

The proximate and ultimate analysis of prepared activated carbon was done and depicted in Table 1 and the results of iodine number and methylene blue number of both the standards and prepared activated carbon determined ${ }^{16}$ according to ASTM D4607-94-2006 are shown in Table 3. It can be found in the results that the iodine number of adsorbents increases in the order F-400 (coal based-std-1) < S.D.Fine (CS based-std-2) <ASAC (Prepared) while it can be observed that methylene blue number of the adsorbents increases in the order S.D.Fine (CS based-std-2) < F-400 (coal based-std-1) < ASAC (Prepared). It is obvious that the prepared activated carbon is having both high micropore and mesopore volume and it can be potentially used for phenol as well as dye removal from aqueous waste. Again the B.E.T surface area of prepared activated carbon is found to be $1358 \mathrm{~m}^{2} / \mathrm{g}$ which shows that it is comparable and better to the findings of earlier researchers ${ }^{17}$.

\section{SEM morphology analysis}

The surface morphology of activated carbon was examined by using a JEOL scanning electron microscope (JSM-6380). The pore formation of activated carbon is mainly attributed to the addition of phosphoric acid which causes the ASAC to swell and it opens the surface structure. Phosphoric acid is a strong dehydrating agent, it has been reported that $\mathrm{H}_{3} \mathrm{PO}_{4}$ accelerated the bond cleavage reactions leading to the early evolution of volatiles at below $300{ }^{\circ} \mathrm{C}$ and generation of empty spaces. At high temperatures the reactive sites leave a hard aromatic carbon porous structure for adsorption ${ }^{18}$. Figures 2 and 3 shows the surface morphology of raw and activated almond shells. In raw almond shells there are no or minimal pores on the surface whereas it can be observed from Figure 2 that the surface shows a lot of grooves, cracks and crevices in the surface matrix after activation. The macropores are highly developed deep inside the surface. Surrounding the surface, plenty of micropores can be observed leaving greater adsorption sites for phenols. It indicates that the precursor material and method for preparation of activated carbon is adequate for the purpose.

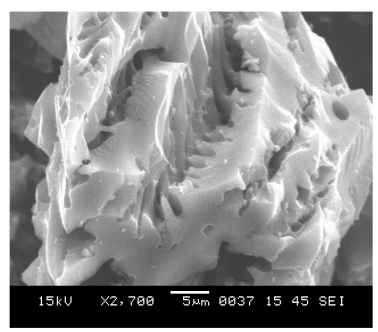

Figure 2. SEM micrograph of ASAC

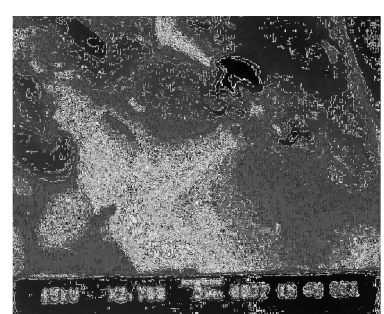

Figure 3. SEM micrograph of raw ASAC 


\section{FTIR spectral analysis}

Details of functional groups present on the surface of carbon materials are obtained from FT-IR studies as shown in Figure 4. A sharp band at $3689 \mathrm{~cm}^{-1}$ is ascribed to isolated nonbonded ydroxyl $(\mathrm{OH})$ groups and around $3526 \mathrm{~cm}^{-1}$ is due to carboxylic acid group. A wide, intense band in the range of $3200-3600 \mathrm{~cm}^{-1}$ with a maximum at about $3445 \mathrm{~cm}^{-1}$ is assigned to the $\mathrm{O}-\mathrm{H}$ stretching mode of hydroxyl groups and adsorbed water ${ }^{19}$. A medium band of symmetric $\mathrm{C}-\mathrm{H}$ stretching vibration at $2882 \mathrm{~cm}^{-1}$ is due to the presence of methyl group on surface. A carbonyl group $\mathrm{C}=\mathrm{O}$ stretch is at $1628 \mathrm{~cm}^{-1}$ and a strong absorption at $1279 \mathrm{~cm}^{-1}$ is for $\mathrm{C}-\mathrm{O}$ stretch due to alcoholic group .

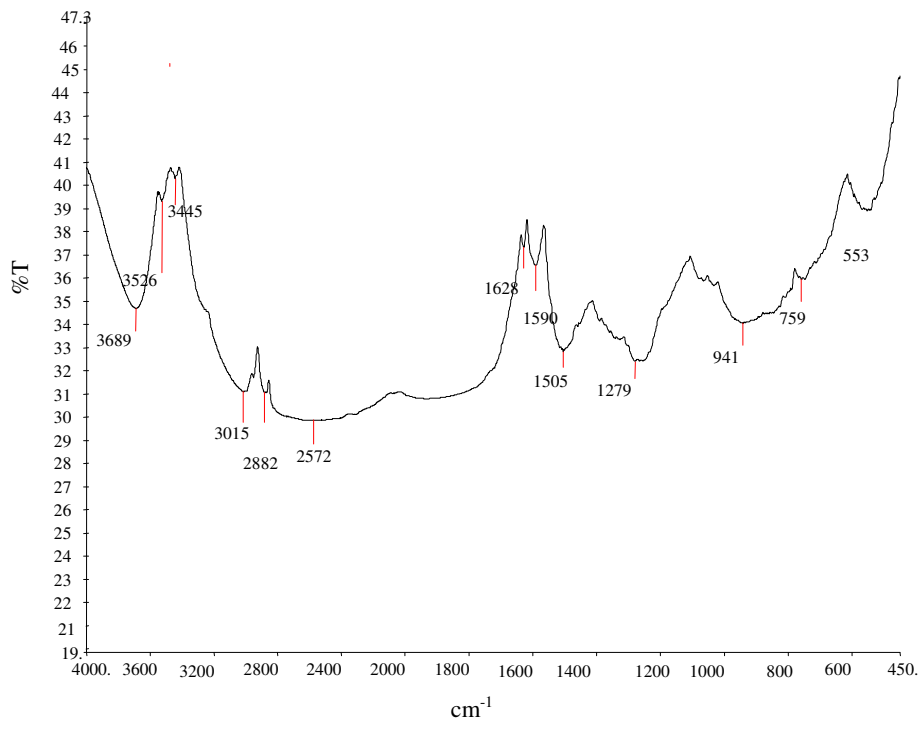

Figure 4. FTIR Spectra of ASAC

The strong absorption at $1505 \mathrm{~cm}^{-1}$ is due to $\mathrm{C}-\mathrm{C}$ stretch and at $1590 \mathrm{~cm}^{-1}$ a weak band is obtained due to conjugated $\mathrm{C}=\mathrm{C}$ stretch respectively are present in ring aromatics. Bands below 1000 are noisy vibrations.

\section{Conclusion}

In this investigation, $\mathrm{H}_{3} \mathrm{PO} 4$ was used for activating the $\mathrm{AS}$ and it enhanced the surface property to a desirable level. It was clearly established from SEM micrographs that highly developed mesopores and micropores are available for adsorption. The FTIR spectra revealed that the hydroxyl group is present for phenolic binding sites. Maximum sorption was achieved at $250 \mathrm{rpm}$ shaking speed, for $72 \mathrm{~h}$.

Studies indicated that the ASAC can be effectively used for the quantitative removal of dyes and phenols. The removal of phenol from aqueous solution is possible by using abundantly available low cost almond shell adsorbents.

\section{Acknowledgement}

The authors are thankful to the Director CIMFR for constant encouragement and providing facilities to carry out this research work with permission to publication. 


\section{References}

1. Gupta V K, Jain C K, Chandra S, Imran A and Agarwal S, Water Res., 2002, 36(10), 2483-2490.

2. Hameed B H, Tan I A W and Ahmad A L, J Hazard Mater., 2009, 164, 1316-1324.

3. Alhakimi G, Studnicki L H and Al-Ghazali M, J Photochem Photobiol A: Chem., 2003, 154, 219-228.

5. Liu G, Ma J, Li X and Qin Q, J Hazard Mater., 2009, 164(2-3), 1275-1280.

6. Tan I A W, Ahmad A L and Hameed B H, J Hazard Mater., 2008, 154(1-3), 337-346.

7. Bansal R C, Donnet J B and Stockli F, Active Carbon, Marcel Decker, New York, 1988.

8. Bevia F R, Rico D P and Gomis A F M, Ind Eng Chem Prod Res Dev., 1984, 23, 266-269.

9. Rodriguez-Reinoso F, Lopez-Gonzalez J. de D and Berenguer C, Carbon, 1982, 20, 513-518.

10. Heschel W and Klose E, Fuel, 1995, 74(12), 1786-1791.

11. López M, Labady M and Laine J, Carbon, 1996, 34(6), 825-827.

12. Jagtoyen M and Derbyshire F, Carbon, 1993, 31(7), 1185-1192.

13. Jagtoyen M and Derbyshire F, Carbon, 1998, 36(7-8), 1085-1097.

14. Ruiz Bevia F, Prats Rico D, and Marcilla Gomis A F, Ind Eng Chem Prod Res., Dev., 1984, 23(2), 266-269; DOI: 10.1021/i300014a019

15. Oliveria E A, Montanher S F, Andrade A D, Nobrega J A and Rollemberg M C, Proc Biochem., 2005, 40, 3485-3490.

16. ASTM D4607-94, Standard Test Method for Determination of Iodine Number of Activated Carbon, 2006, 1-5.

17. Bansode R R, Losso J N, Marshall W E, Rao R M and Portier R J, Bioresour Technol., 2003, 90(2),175-184.

18. Buchnan F J and Little J A, Surf Coat Technol., 1991, 46(2), 217-226.

19. Madhava Rao M, Ramesh A, Purna Chandra Rao G and Seshaiah K, J Hazard Mater., 2006, B129(6), 123-129. 